\title{
GIGI LANSIA
}

\author{
Asep Arifin Senjaya \\ Dosen Jurusan Keperawatan Gigi Poltekkes Denpasar \\ aseparifinsenjaya@yahoo.com
}

\begin{abstract}
Projected in 2025, Indonesia will experience an increase in the number of elderly in the world. Tooth has a function for chewing, speaking, and aesthetics. Tooth loss in the elderly have an impact on a variety of issues. Data Basic Health Research in 2013 in Bali showed that, the age group 55-64 years had the highest proportion in oral health issues, namely $30.8 \%$. Elderly are expected to at least have 20 teeth function. Tooth loss in the elderly have an impact on a variety of issues, including the psychological effects such as feeling embarrassed, tension, loss of appetite, malnutrition, disturbed sleep, trouble getting along, dodge to get out, do not have friends, impaired concentration, until it can not work in total. Elderly is a natural process that can not be avoided. Signs of physical deterioration in the elderly, among others: a) skin begins to loosen and the wrinkled face and lines are settled; b) hair graying and white; c) gear slowly start date until toothless; d) visual acuity and hearing loss; e) easily tired; f) the movement began to slow and less agile; g) lean body fat deposits disappear and occur in several parts of the body. The purpose of writing this article is to provide information that the teeth have an important role in the lives of the elderly.
\end{abstract}

Keywords: tooth; elderly

\begin{abstract}
Abstrak: Diproyeksikan pada tahun 2025, Indonesia akan mengalami peningkatan jumlah lansia terbesar di dunia. Gigi memiliki fungsi untuk pengunyahan, berbicara, dan estetika. Kehilangan gigi pada lansia berdampak pada berbagai persoalan. Data Riset Kesehatan Dasar tahun 2013 di Provinsi Bali menunjukan bahwa, kelompok usia 55 - 64 tahun memiliki proporsi tertinggi dalam permasalahan kesehatan gigi dan mulut, yaitu 30,8\%. Lansia diharapkan minimal mempunyai 20 gigi berfungsi. Kehilangan gigi pada lansia berdampak pada berbagai persoalan, di antaranya dampak psikologis seperti merasa malu, tegang, kehilangan selera makan, malnutrisi, tidur terganggu, kesulitan bergaul, menghindar untuk keluar, tidak memiliki teman, konsentrasi terganggu, hingga tidak dapat bekerja secara total. Lansia merupakan proses alamiah yang tidak dapat dihindarkan. Tanda-tanda kemunduran fisik pada lansia antara lain: a) kulit mulai mengendur dan pada wajah timbul keriput serta garis-garis yang menetap; b) rambut mulai beruban dan menjadi putih; c) gigi perlahan-lahan mulai tanggal hingga ompong; d) ketajaman penglihatan dan pendengaran berkurang; e) mudah lelah; f) gerakan mulai lamban dan kurang lincah; g) kerampingan tubuh menghilang dan terjadi timbunan lemak di beberapa bagian tubuh. Tujuan penulisan artikel ini adalah untuk memberikan informasi bahwa gigi memiliki peran yang penting dalam kehidupan lansia.
\end{abstract}

Kata kunci: gigi, lansia. 


\section{Pendahuluan}

Berdasarkan data UNFPA, di dunia saat ini terdapat sekitar 737 juta jiwa penduduk lanjut usia (lansia), yaitu usia 60 tahun lebih. Berdasarkan jumlah tersebut sekitar dua pertiga tinggal di negara - negara berkembang, termasuk di Indonesia. Data BPS tahun 2010 mencatat jumlah penduduk Indonesia yaitu sebanyak 237.641.326 jiwa dan sekitar 20 juta orang adalah penduduk lansia. ${ }^{1}$ Sensus Penduduk tahun 2010 menunjukkan bahwa Indonesia termasuk lima besar negara dengan jumlah penduduk lansia terbanyak di dunia yaitu 18,1 juta jiwa atau 9,6\% dari jumlah penduduk Indonesia. Jumlah lansia tersebut meningkat sebanyak empat kali lipat dibandingkan pada tahun 1970 yang tercatat sekitar 5,3 juta jiwa atau 4,48\% dari jumlah penduduk saat itu. Meningkatnya jumlah lansia seiring dengan meningkatnya angka usia harapan hidup penduduk Indonesia sehingga jumlah lansia bertambah dengan cepat. $^{2}$ Indonesia akan mengalami peningkatan jumlah populasi lansia yang luar biasa, pada tahun 2025 diproyeksikan sebesar 414\%, ini terbesar di dunia. Hal ini mendorong kita semua untuk bersiap menghadapinya, yaitu dalam menghadapi konsekuensi logis akan adanya berbagai masalah yang muncul, seiring dengan ledakan populasi lansia ini. ${ }^{1}$

Lanjut usia adalah setiap orang yang berusia 60 tahun atau lebih, yang secara fisik terlihat berbeda dengan kelompok umur lainnya. Umumnya setiap orang akan mengalami proses menjadi tua dan masa tua adalah masa hidup manusia yang terakhir. Pada masa ini seseorang mengalami kemunduran fisik, mental, dan sosial hingga tidak melakukan tugasnya sehari-hari lagi dan bagi kebanyakan orang masa tua kurang menyenangkan. ${ }^{3}$

Gigi memiliki fungsi untuk pengunyahan, berbicara, dan estetika. Gigi - geligi pada lansia mungkin sudah banyak yang rusak, bahkan copot sehingga memberikan kesulitan saat mengunyah makanan. ${ }^{3}$ Berkurangnya kemampuan mencerna makanan akibat kerusakan gigi atau ompong merupakan salah satu faktor yang mempengaruhi kebutuhan gizi lansia. ${ }^{4}$ Kehilangan gigi pada lansia 
berdampak pada berbagai persoalan, di antaranya dampak psikologis seperti merasa malu, tegang, kehilangan selera makan, malnutrisi, tidur terganggu, kesulitan bergaul, menghindar untuk keluar, tidak memiliki teman, konsentrasi terganggu, hingga tidak dapat bekerja secara total. ${ }^{5}$ Kesehatan gigi merupakan salah satu aspek dari kesehatan seseorang yang merupakan hasil interaksi dari kondisi fisik, mental, dan sosial. ${ }^{6}$

Kehilangan gigi merupakan penyebab terbanyak menurunnya fungsi pengunyahan. Kehilangan gigi juga dapat mempengaruhi rongga mulut dan kesehatan umum sehingga akan mempengaruhi kualitas hidup seseorang secara keseluruhan. Kehilangan gigi dapat disebabkan oleh berbagai hal. Penyebab terbanyak kehilangan gigi adalah akibat buruknya status kesehatan rongga mulut, terutama karies dan penyakit periodontal. ${ }^{3}$ Hasil Riset Kesehatan Dasar tahun 2013 di Provinsi Bali berdasarkan kelompok usia diperoleh data bahwa, kelompok usia 55 - 64 tahun memiliki proporsi tertinggi dalam permasalahan kesehatan gigi dan mulut, yaitu
30,8\%. ${ }^{7}$ Lansia diharapkan minimal mempunyai 20 gigi berfungsi, hal ini berarti bahwa fungsi pengunyahan mendekati normal, walaupun sedikit berkurang. Demikian halnya fungsi estetik serta fungsi bicara masih dapat dianggap normal dengan jumlah gigi minimal 20 buah. $^{8}$

Tujuan penulisan artikel ini adalah untuk memberikan informasi pentingnya gigi dalam kehidupan lansia.

\section{Pembahasan}

\section{Pengertian Lansia}

Lansia merupakan proses seseorang bertambah tua, merupakan interaksi yang kompleks dari segi biologis, psikologis, dan sosiologis. Lansia adalah seseorang yang berusia 60 tahun atau lebih, yang secara fisik terlihat berbeda dengan kelompok umur lainnya.

Berdasarkan kelompok usia, lansia dibagi menjadi tiga, yaitu: a) kelompok pertama adalah kelompok pra lansia 45 - 59 tahun; b) kelompok kedua adalah kelompok lansia 60 69 tahun; c) kelompok ketiga adalah kelompok lansia risiko tinggi yaitu usia lebih dari 70 tahun. ${ }^{1}$

Lansia merupakan proses alamiah yang tidak dapat 
dihindarkan. Secara biologis akan terjadi kemunduran - kemunduran fisik pada lansia, tanda-tanda kemunduran fisik antara lain: a) kulit mulai mengendur dan pada wajah timbul keriput serta garis-garis yang menetap; b) rambut mulai beruban dan menjadi putih; c) gigi perlahanlahan mulai tanggal hingga ompong; d) ketajaman penglihatan dan pendengaran berkurang; e) mudah lelah; f) gerakan mulai lamban dan kurang lincah; g) kerampingan tubuh menghilang dan terjadi timbunan lemak di beberapa bagian tubuh. ${ }^{9}$

Maryam, dkk. menyatakan bahwa, proses menua pada lansia menyebabkan terjadinya tanda tanda penuaan, yaitu berupa: ${ }^{10}$

\section{Perubahan sistem integumen.}

Perubahan sistem integumen terjadi pada kulit lansia, sehingga kulit lebih mudah rusak, mengerut/ keriput yang diakibatkan hilangnya jaringan lemak. Permukaan kulit menjadi kasar dan bersisik dikarenakan hilangnya proses kreatinisasi serta perubahan ukuran dan bentuk sel - sel epidermis. Kulit kepala dan rambut menipis dan berwarna kelabu, rambut dalam hidung dan telinga menebal. Penurunan cairan dan vaskularisasi mengakibatkan berkurangnya elas-tisitas, sehingga kuku menjadi keras, rapuh, pudar, tidak bercahaya, dan partumbuhannya melambat. Kelenjar keringat berkurang baik jumlah maupun fungsinya.

\section{Perubahan sistem muskuloskeletal.}

Perubahan sistem muskuloskeletal yang terjadi pada tulang yaitu kehilangan kepadatan tulang sehingga menjadi rapuh, kehilangan cairan sendi menyebabkan persendian menjadi kaku, pergerakan terbatas, dan sendi membesar. Tendon mengerut dan mengalami sclerosis, juga adanya atrofi serabut otot sehingga gerakan melambat, otot mudah kram dan tremor, kecuali otot polos tidak begitu terpengaruh.

\section{Perubahan sistem kardiopulmonal.}

Pada sistem kardiovaskuler terjadi perubahan, yaitu arteri kehilangan elastisitasnya. Elastisitas aorta menurun, katup pada jantung menebal dan menjadi kaku. Sehingga menurunkan kemampuan jantung, peningkatan nadi, dan tekanan sistolik darah.

Perubahan sistem pencernaan dan metabolisme. 
Pada sistem pencernaan dan metabolisme terjadi kehilangan gigi akibat penyakit periodontal. Kesehatan gigi yang buruk, gizi yang buruk, dan berkurangnya kekuatan otot rahang akan menyebabkan kelelahan pada lansia saat mengunyah makanan. Iritasi kronis pada selaput lendir mengakibatkan atrofi indera pengecap dan berkurangnya sensitifitas syaraf pengecap yang menurunkan kemampuan indera pengecap hingga terjadi penurunan selera makan yang pada akhirnya berdampak defisiensi nutrisi dan malnutrisi pada lansia.

\section{Perubahan sistem neurologis.}

Berbagai penyakit dan faktor lingkungan yang telah berinteraksi sepanjang hidupnya lansia, berdampak pada kerusakan sel - sel di otak. Kelainan yang timbul tergantung jumlah kerusakan serta area otak yang terkena kerusakan. Perubahan terbesar yang terjadi pada lansia meliputi lemahnya ingatan, menurunnya kemampuan kognitif, perubahan pola tidur, gangguan pada: penglihatan, pendengaran, kemampuan berjalan, dan postur tubuh.

\section{Perubahan sistem pendengaran.}

Perubahan pada organ pendengaran yang berhubungan dengan penam-bahan usia berupa: daun telinga lebih besar, ini dikarenakan pembentukan tulang rawan yang berlanjut dan penurunan elastisitas kulit. Saluran telinga pada lansia menyempit dan rambut pada saluran telinga lebih kasar dan kaku.

\section{Perubahan sistem penglihatan.}

Pada lansia jaringan lemak menyelimuti bola mata, membran mukosa konjungtiva menjadi kering karena berkurangnya kualitas dan kuantitas air mata, sklera menjadi kecoklatan, ukuran pupil dan iris menjadi lebih kecil dan mengalami penurunan kemampuan kontriksi, sehingga membatasi jumlah cahaya yang masuk ke mata. Terjadi kekeruhan pada lensa mata yang berakibat katarak. Ambang pengamatan sinar meningkat, daya adaptasi terhadap kegelapan lebih lambat, hal ini mengakibatkan sulit melihat dalam suasana gelap. Pada akhirnya semua ini berdampak pada penurunan kemampuan penglihatan lansia. 
Kesehatan Gigi dan Mulut Lansia

Akibat bertambahnya usia secara berangsur-angsur gigi berkurang karena tanggal. Ketidaklengkapan gigi tentunya akan dapat mengurangi kenyamanan makan dan membatasi jenis-jenis makanan yang dikonsumsi. Produksi air liur dengan berbagai enzim yang dikandungnya juga mengalami penurunan, sebagai akibatnya dapat menimbulkan mulut kering, kemampuan mengecap makanan berkurang, dan kemungkinan mempercepat terjadinya penimbunan karang gigi. Faktor-faktor penting yang dapat mempengaruhi kesehatan gigi pada lansia di antaranya adalah kurangnya produksi saliva serta kebiasaan membersihkan gigi dan mulut. Karies gigi dan penyakit periodontal merupakan penyebab utama kehilangan gigi pada lansia. ${ }^{9}$

Kehilangan sebagian maupun seluruh gigi dapat menimbulkan dampak emosional, sistemik, maupun fungsional. Dampak emosional di antaranya: hilangnya kepercayaan diri, perasaan sedih, depresi, merasa kehilangan bagian tubuh, dan merasa tua. Dampak sistemik yaitu berupa penyakit kardiovaskular, osteoporosis, dan penyakit gastro- intestinal, seperti kanker eusofagus, kanker lambung, dan kanker pankreas. Dampak fungsional kehilangan gigi yaitu gangguan bicara dan gangguan pengunyahan. ${ }^{11}$

Kurang menjaga kebersihan gigi bisa berimplikasi masuknya bakteri yang berujung pada banyak masalah kesehatan yang umum seperti penyakit jantung dan penyakit lainnya. Penyakit di rongga mulut pada lansia dapat berakibat negatif terhadap kesehatan dan kualitas hidup lansia secara keseluruhan. Beberapa kondisi yang sering terjadi pada rongga mulut lansia: a) kehilangan gigi; b) penyakit gusi; c) mulut kering/ xerostomia; d) periodontitis. Melalui perawatan yang baik gigi dapat bertahan selama mungkin di rongga mulut. ${ }^{12}$

Status kesehatan gigi lansia dipengaruhi oleh beberapa faktor yang saling berinteraksi $\left.{ }^{13}: 1\right)$ Faktor dari diri lansia sendiri, berupa: jenis kelamin, usia, perilaku hidup, pendidikan, pekerjaan, status perkawinan, perumahan, dan status sosial ekonomi; 2) Faktor keluarga, seperti: jumlah generasi, pola tinggal, dan peri-laku keluarga dalam pemeliharaan kesehatan gigi; 3) 
Faktor lingkungan, seperti keadaan sosial budaya; Faktor pelayanan kesehatan gigi, berupa: keberadaan program kesehatan gigi lansia, sikap dan perilaku petugas kesehatan saat memberikan pelayanan kesehatan.

\section{Pencegahan Kerusakan Gigi}

\section{Lansia}

Para lansia seringkali mengabaikan kebersihan gigi dan mulutnya, mereka sering mengeluh sakit gigi, gigi goyang dan dapat menyebabkan gigi tanggal. Kondisi ini dapat dicegah dengan pemeliharaan kebersihan gigi dan mulut yaitu dengan menggosok gigi secara teratur agar pembentukan bakteri dalam mulut dapat dicegah. Hal ini dapat dilakukan secara teratur dan berkesinambungan dimulai dari diri sendiri dengan cara $^{13}:$ 1) Menjaga kebersihan gigi dan mulut dengan menyikat gigi secara teratur dan membersihkan gusi dengan baik. Bagi yang tidak ada gigi dengan menggunakan kapas yang dicelupkan ke dalam air hangat, tujuan pembersihan ini untuk menghindari tumbuhnya jamur pada gusi; 2) Mengatur pola makan dengan menghindari makanan yang dapat merusak gigi seperti banyak mengandung gula; 3) Pemeriksaan gigi secara teratur ke dokter gigi, Puskesmas, ataupun Rumah Sakit setiap enam bulan sekali untuk mengetahui kelainan yang ada pada mulut sejak dini.

Kegiatan yang harus dilakukan selain seperti di atas, para lansia juga perlu diberi tindakan pencegahan penyakit gigi dan mulut seperti dalam pelaksanaan asuhan keperawatan. Berbagai upaya perlu diperhatikan baik oleh lansia, keluarga, maupun petugas kesehatan yang melaksanakannya, antara lain ${ }^{13}$ :

\section{Upaya promotif}

Dengan memberikan penyuluhan tentang: a) cara pemeliharaan kesehatan gigi dan mulut.; b) pentingnya protesa untuk mengembalikan fungsi kunyah; c) pemeriksaan secara berkala

\section{Upaya preventif}

Berupa: a) pemeliharaan gigi dan mulut termasuk protesanya; b) pemilihan jenis makanan yang mudah dikunyah dan dicerna ; c) deteksi dini bila ada kelainan mukosa untuk mencegah keganasan sehingga segera melakukan pemeriksaan; d) pemeriksaan berkala ke dokter gigi. 
Upaya kuratif dan rehabilitatif.

Perawatan diri untuk lansia dalam menjaga kebersihan gigi dan mulutnya, yaitu $\left.{ }^{12}: 1\right)$ Untuk yang masih mempunyai gigi: a) bila ada karang gigi dan atau gigi berlubang sebaiknya segera ke dokter gigi untuk mendapatkan penanganan lebih lanjut; 2) Menyikat gigi secara teratur minimal dua kali dalam sehari, pagi dan malam sebelum tidur; 3) Bagi lansia yang menggunakan gigi palsu lepasan, maka gigi palsu tersebut disikat dengan sikat gigi perlahan - lahan di bawah air mengalir, bila perlu dapat menggunakan pasta gigi. Waktu tidur gigi palsu tersebut dilepas dan direndam di dalam air bersih; 4) Bagi lansia yang tidak mempunyai gigi sama sekali, setiap habis makan seharusnya langsung berkumurkumur dan juga menyikat bagian gusi dan lidah secara teratur untuk membersihkan sisa makanan yang melekat.

Sepuluh langkah agar dapat hidup lebih lama, sehat, dan berarti untuk lansia yaitu: 1) Menciptakan pola makan yang baik, kemudian bersahabat dengannya. Ciptakan suasana yang menyenangkan di meja makan sehingga dapat menimbulkan selera makan; 2) Memperkuat daya tahan tubuh, dengan mengkonsumsi makanan yang mengandung zat gizi yang penting untuk kekebalan, seperti: biji-bijian utuh, sayuran hijau, makanan laut; 3) Mencegah tulang agar tidak menjadi keropos dan mengkerut, dengan makanan yang mengandung vitamin D. Pada usia diatas 60 tahun kemampuan penyerapan kalsium menurun, vitamin $\mathrm{D}$ membantu penye-rapan kalsium dalam tubuh, contoh makanan sumber vitamin D adalah susu; 4) Memastikan agar saluran pencernaan tetap sehat, aktif dan teratur. Untuk itu harus makan sedikitnya 20 gram makanan yang mengandung serat seperti biji-bijian, jeruk, dan sayuran yang berdaun hijau tua; 5) Menyelamatkan penglihatan dan mencegah terjadinya katarak dengan makanan yang mengandung vitamin $\mathrm{C}, \mathrm{E}$, dan $\mathrm{B}$, serta antioksidan; 6) Mengurangi risiko penyakit jantung dengan membatasi makanan berlemak yang banyak mengandung kolesterol dan natrium serta harus banyak makan makanan yang kaya vitamin B6, $\mathrm{B} 12$, asam folat, serat yang larut 
dalam air, kalsium, dan kalium; 7) Agar ingatan tetap baik dan sistem syaraf tetap bagus, harus banyak makan vitamin B6, B 12, dan asam folat; 8) Mempertahankan berat badan ideal dengan jalan tetap aktif secara fisik, makan rendah lemak dan kaya akan karbohidrat kompleks; 9) Menjaga agar nafsu makan tetap baik dan otot tetap lentur, dengan cara melakukan olah raga aerobik, berjalan, atau berenang. Olah raga dilakukan menurut porsi masingmasing usia serta tingkat kebugaran setiap orang; 10) Tetap beraktifitas setiap hari. $^{14}$

\section{Simpulan dan Saran}

Berdasarkan pembahasan di atas dapat disimpulkan bahwa, lansia harus tetap memelihara giginya sehingga minimal memiliki 20 gigi berfungsi agar dapat mengunyah makanan dengan baik. Pengunyahan makanan yang baik serta pemenuhan kebutuhan gizi yang seimbang akan turut menjaga agar lansia tetap sehat.

Agar lansia dapat hidup lebih lama, sehat, dan berarti disarankan untuk tetap menjaga pola hidup sehat serta beraktifitas setiap hari.

\section{Daftar Pustaka}

1. Wiwik Indraswari, A. Razak Thaha, Nurhaedar Jafar. Pola Pengasuhan Gizi dan Status Gizi Lanjut Usia Puskesmas Lau Kabupaten Maros Tahun 2012, pasca.unhas.ac.id /jurnal/files/58c4192eb29f12d85 3198579fb322c33.pdf ( di akses 13 Januari 2017)

2. BPS. Statistik Penduduk Lanjut Usia 2014; Hasil Survei Sosial Ekonomi Nasional, Jakarta: Badan Pusat Statistik, 2015. Di akses 12 Januari 2016 pada http://www.bps.go.id.

3. Departemen Kesehatan R.I. Pedoman Puskesmas Santun Usia Lanjut. Jakarta: t.p; 2003.

4. Akhdrisa Mura Wijaya, I Dewa Putu Pramantara, Retno Pangastuti. Status Kesehatan Oral dan Asupan Zat Gizi Berhubungan dengan Status Gizi Lansia, Jurnal Gizi Klinik Indonesia, Vol. 8, No. 3, Januari 2012:151-157 di akses 12 Januari 2017 pada alamat http://ijn.or.id/download/vol8no3 Jan2012/AkhdrisaMW.pdf

5. Pasiga B. Dampak Sosial Akibat Kondisi Gigi dan Mulut Kelompok Lanjut, Majalah Ilmiah Kedokteran Gigi (Edisi Khusus Foril VII), hal. 257-259. 2002.

6. Setyaningsih D. Menjaga Kesehatan Gigi dan Mulut. Jakarta: CV Sinar Cemerlang Abadi. 2007.

7. Kementerian Kesehatan R.I. Gambaran Kesehatan Lanjut Usia di Indonesia: (diakses tanggal 3 Maret 2016. Tersedia pada http://www. depkes.go.id/downloadpdf/buleti n-lansia-pdf. 
8. Kementerian Kesehatan R.I. Buku Panduan Pelatihan Kesehatan gigi dan Mulut Kader Posyandu. Jakarta: t.p. 2012.

9. Departemen Kesehatan R.I. Pedoman Pembinaan Kesehatan Usia Lanjut Bagi Petugas Kesehatan. Jakarta: t.p. 2001.

10. Riadiani, Bunga; Sari Dewi,Ratna; Ariani, Nina; Gita Farisza, Toot Loss Perceived Masticatory Ability in PostMenopousal Women, Journal of Dentistry Indonesia 2014, vol.21, no.111-15doi:

10.146393/jdi.voi0.2012 diakses 12 Januari 2017 pada http://www.jdentistry.ui.ac.id/ind ex.php/JDI/article/view/212/0

11. Hendari, Ratnawati. Pemutihan Gigi (Tooth-Whitening) Pada Gigi yang Mengalami Pewarnaan ( Dosen Jurusan Kesehatan Gigi Politeknik Kesehatan Semarang) Majalah Ilmiah Sultan Agung Vol 47, No 118 (2009): Jurnal Majalah Ilmiah Sultan Agung, Juni Agustus 2009 Publisher: Universitas Islam Sultan Agung
12. Siska Anggreni. Tesis, Jumlah dan bentuk Akar serta Konfigurasi saluran akar Gigi Molar satu Rahang atas dan bawah. Jakarta. Universitas Indonesia, 2012 di akses tanggal 13 Januari 2016 di : http://lib.ui.ac/digital)

13. Rahardjo dan Tri B. W. Kebijakan Tentang Kesejahteraan Penduduk Lansia Di Indonesia Serta Kaitannya Dengan Upaya Pembinaan Kesehatan, Termasuk Bidang Kesehatan Gigi, Majalah Ilmiah Kedokteran Gigi 1 (Edisi Khusus Foril V 1996), hal. 68-78. 1996.

14.Wasilah Rocmah, Soedjono Aswin. Tua dan Proses Menua, Yogyakarta, Fakultas Kedokteran Universitas Gadjah Mada (Berkala Ilmu Kedokteran, Vol.33, No. 4, 2001) diakses 12 Januari 2017 pada http://download.portalgaruda.or g/article.php? article $=283381 \& \mathrm{v}$ $a l=5016 \&$ title $=$ Aged $\% 20$ and $\% 2$ OAging 